\title{
Temperature CoefFicient for Modeling Denitrification in Surface Water Sediments Using THe Mass Transfer COEFFicient
}

\author{
T. W. Appelboom, G. M. Chescheir, F. Birgand, R. W. Skaggs, J. W. Gilliam, D. Amatya
}

\begin{abstract}
Watershed modeling has become an important tool for researchers. Modeling nitrate transport within drainage networks requires quantifying the denitrification within the sediments in canals and streams. In a previous study, several of the authors developed an equation using a term called a mass transfer coefficient to mathematically describe sediment denitrification. This equation takes into account the effect that water column nitrate concentration and flow depth have on denitrification in the sediments. Water column temperature also has a marked effect on the rate of denitrification in the sediments. In the present study, a relationship between denitrification rate and temperature was developed. This relationship was inserted into the original mathematical relationship to improve its ability to predict nitrate removal due to denitrification within drainage networks. The modified equation was tested by comparing predicted and measured nitrate concentrations over time in denitrification tanks at various temperatures. Results show that the modified equation increased the accuracy of predicting nitrate removal by denitrification in drainage canals. Overall Nash-Sutcliffe model efficiency values ranged from 0.72 to 0.76 for the original equation and from 0.90 to 0.97 for the equation developed in this study. The effective temperature range for the equation is $0^{\circ} \mathrm{C}$ to $40^{\circ} \mathrm{C}$. The equation has also only been tested under stagnant/low-flow conditions.
\end{abstract}

Keywords. Denitrification, Mass transfer coefficient, Modeling, $Q_{10}$ temperature coefficient, Temperature, Watershed.

$\mathrm{I}$ ncreasing $\mathrm{N}$ loads have caused degradation of receiving waters (Rabalais et al., 2002; NRC, 2000; Smith et al., 1999). Sources of nitrogen loads include nonpoint sources from agricultural, urban, and managed forest lands as well as point sources from municipal and industrial treatment facilities (Poor et al., 2001). Financial assistance and management practices have been proposed and implemented to reduce $\mathrm{N}$ loads from both point and nonpoint sources (e.g., Brown et al., 2009; NRCS, 2009; CWSRF, 1987). Current research has focused on analyzing these reductions and developing methods to predict $\mathrm{N}$ loads from managed lands, as well as methods of determining the cumulative impact of management practices on $\mathrm{N}$ loads at the outlets of large watersheds (Fernandez et al., 2005; Amatya et al., 2004; Skaggs and Chescheir, 1999; Arnold et al., 1998;

Submitted for review in November 2008 as manuscript number SW 7819; approved for publication by the Soil \& Water Division of ASABE in March 2010. Presented at the 2006 International Conference on Hydrology and Management of Forested Wetlands as Paper No. 701P046.

The authors are Timothy W. Appelboom, ASABE Member Engineer, Research Associate, George M. Chescheir, ASABE Member Engineer, Research Associate Professor, François Birgand, ASABE Member Engineer, Assistant Professor, and R. Wayne Skaggs, ASABE Fellow, William Neal Reynolds Professor and Distinguished University Professor, Department of Biological and Agricultural Engineering, North Carolina State University, Raleigh, North Carolina; J. Wendell Gilliam, Retired Professor, Department of Soil Science, North Carolina State University, Raleigh, North Carolina; and Devendra M. Amatya, ASABE Member Engineer, Research Hydrologist, USDA Forest Service, Charleston, South Carolina. Corresponding author: TimothyW.Appelboom, Biological and Agricultural Engineering Department, North Carolina State University, Raleigh, NC 27695-7625; phone: 919-515-6763; fax: 919-515-7760 e-mail: twappelb@ncsu.edu.
Heatwole et al., 1987). Important tools for this determination are watershed models that can predict $\mathrm{N}$ loads from individual fields and route it through the drainage network to the watershed outlet (Fernandez et al., 2005; Amatya et al., 2004). Algorithms for simulating the in-stream processes that remove nitrogen from the water as it moves through the streams are very important components of these models.

Research since 1970 has shown that nitrogen can be removed from water as it flows through a stream and canal network (e.g., Duff and Triska, 1990; Wyer and Kay, 1989; Hill, 1988; Triska et al., 1984; Meyer et al., 1981). The main mechanism for $\mathrm{N}$ removal in streams is denitrification. Denitrification has been identified as the only method that truly removes nitrogen from the system (Bigand et al., 2007; Jensen et al., 1994, reviewed by Seitzinger, 1988; Hill and Sanmagadas, 1985; Swank and Caskey, 1982; Chatarpaul et al., 1979). Other in-stream processes that remove nitrogen included assimilation by macrophytes and algae and emergent drift; however, these processes are usually not as significant in nitrate polluted streams (concentrations greater than $1 \mathrm{mg}$ $\left.\mathrm{N} \mathrm{L}^{-1}\right)$.

Denitrification is the reduction of nitrate $\left(\mathrm{NO}_{3}\right)$ to gaseous nitrous oxide $\left(\mathrm{N}_{2} \mathrm{O}\right)$ and elemental $\mathrm{N}\left(\mathrm{N}_{2}\right)$ (Tisdale et al., 1993). It occurs in the anaerobic sediments along the bottom of a river or stream. Denitrification rates are affected by many factors, such as presence of oxygen, $\mathrm{pH}$, organic carbon supply, temperature, nitrate supply, and denitrifier population levels (Tisdale et al., 1993; Swank and Caskey, 1982; Van Kessel, 1977). In stream ecosystems, denitrification occurs in a zone that encompasses the upper sediments along the bottom of the stream. This zone, the hyporheic zone (Hynes, 
1983), is divided into two parts: an upper aerobic portion and a lower anaerobic portion.

Birgand et al. (2007) conducted a comprehensive review of the current literature related to nitrogen removal in nitrate polluted streams. They discussed the main factors affecting nitrogen removal and proposed methods for quantifying the processes. Denitrification at the sediment-water interface was identified as the most important stream process for removing nitrogen, with the capacity of removing $10 \%$ to $70 \%$ of the total nitrogen load that enters the stream network in a watershed. Birgand et al. (2007) proposed using the concept of the mass transfer coefficient (Kelly et al., 1987) to quantify nitrogen removal and developed an equation using this coefficient. The mass transfer coefficient is a single lumped coefficient that relates nitrogen removal to the nitrate concentration of the water column and the surface area of the stream bottom.

Numerous studies have shown that the rate of denitrification is influenced by temperature. Dawson and Murphy (1972) observed more than a tenfold increase in denitrification rates as temperature increased from $5^{\circ} \mathrm{C}$ to $27^{\circ} \mathrm{C}$. Van Kessel (1977) observed a proportional increase in denitrification rates with temperature increases from $4^{\circ} \mathrm{C}$ to $25^{\circ} \mathrm{C}$ in water-sediment systems. Other studies (Nowicki, 1994; Seitzinger, 1988; Chalamet, 1985) have documented increases in nitrate removal from water overlying sediment cores with increased temperature. Birgand et al. (2007) reported that instream nitrogen removal rates are greatest in summer and lowest in winter, but other factors besides temperature may be affecting seasonal nitrogen removal rates as well.

Since there is very good evidence that temperature affects in-stream nitrogen removal rates, it seems logical that temperature should be explicitly included in models for predicting nitrogen removal in streams. The objectives of this study were to (1) improve the accuracy and applicability of Birgand's equation by incorporating a temperature term and (2) test the new equation using field data.

\section{MODEL FOR In-STREAM Nitrate REMOVAL}

Under controlled conditions (constant temperature, denitrifier population, water column depth, amount of labile carbon present, and $\mathrm{pH}$ ), water column nitrate removal through denitrification results in the typical exponential decay curve shown in equation 1 :

$$
\left[C_{1}\right]=\left[C_{0}\right]^{*} \mathrm{e}^{\left(-k^{*} t\right)}
$$

where $\left[C_{0}\right]$ is the initial concentration, $\left[C_{1}\right]$ is the concentration at time $t$, and $k$ is the decay coefficient. This relationship allows for the prediction of water column concentration over time rather than using a removal rate at a single concentration. Taking the natural log of both sides, equation 1 may be written as a linear relationship:

$$
\ln \left[C_{1}\right]=-k^{*} t+\ln \left[C_{0}\right]
$$

where $k$, the decay coefficient, is the slope of a straight-line relationship relating time and concentration, with $\ln \left[C_{0}\right]$ being the $y$ intercept.
Denitrification rates have been, and in some instances still are, reported as an overall average in units of mass per unit area over time (e.g., $\mathrm{mg} \mathrm{m}^{-2} \mathrm{~d}^{-1}$ ) without reference to the nitrate concentration or temperature (or range of concentrations and temperatures) at which the denitrification rate is determined. This gives a less usable estimation as denitrification varies with water column nitrate concentration, denitrifier population, temperature, water column depth, amount of labile carbon present, and $\mathrm{pH}$.

Kelly et al. (1987) proposed a term called a mass transfer coefficient $(\rho)$ to predict nitrate removal rates based on differing water column nitrate concentrations and to make comparisons of stream sediment denitrification rates possible. The mass transfer coefficient represents the straight-line relationship of the nitrate removal rate to the water column nitrate concentration (eq. 3):

$$
\rho=R R /[C]
$$

where $\rho$ is the mass transfer coefficient $\left(\mathrm{m} \mathrm{d}^{-1}\right), R R$ is the measured nitrate removal rate $\left(\mathrm{mg} \mathrm{m}^{-2} \mathrm{~d}^{-1}\right)$, and $[C]$ is the measured water column nitrate concentration $\left(\mathrm{mg} \mathrm{m}^{-3}\right)$. The result is a useful term that is an averaged constant over the entire range of water column nitrate concentrations, allowing for easy comparisons of denitrification between different studies as well as predicting a nitrate removal rate for differing nitrate concentrations. However, this equation does not have a time step component for model application, nor does it take into account the effects of denitrifier population, temperature, water column depth, amount of labile carbon present, and $\mathrm{pH}$ on the denitrification; thus, it results in only a rough approximation that is still fairly study specific.

Birgand (2000) derived an equation using Kelly's mass transfer coefficient concept (expanded from a removal rate to mass removal) with a mass balance approach to nitrate removal rate, which contains a depth term and a time step (eq. 4):

$$
\left[C_{1}\right]=\left[C_{0}\right]^{*} \mathrm{e}^{\left(-\rho^{*} t / D\right)}
$$

where $\left[C_{0}\right]$ is the concentration at the beginning of the time step $\left(\mathrm{mg} \mathrm{m}^{-3}\right),\left[C_{1}\right]$ is the concentration at the end of the time step $\left(\mathrm{mg} \mathrm{m}^{-3}\right), t$ is the time step (d), $D$ is the depth of the water column $(\mathrm{m})$, and $\rho$ is the mass transfer coefficient $\left(\mathrm{m} \mathrm{d}^{-1}\right)$. Birgand's equation is a version of the typical exponential decay equation (eq. 1) where $k$, the decay coefficient, is equal to the mass transfer coefficient divided by the depth term $(\rho / D)$. By taking the natural log of both sides of the equation and rearranging, the equation can be solved for the mass transfer coefficient $(\rho)$ (eq. 5):

$$
\rho=\ln \left(\left[C_{1}\right] /\left[C_{0}\right]\right) /(-t / D)
$$

Birgand's equation not only improved the accuracy of the mass transfer coefficient, it also improved the ability to predict changes in water column concentration over a time step, as needed for modeling (Birgand, 2000). But this equation still did not address the effects of denitrifier population, temperature, amount of labile carbon present, and $\mathrm{pH}$ on a denitrification rate. Of these factors, temperature has the greatest effect on denitrification rates, is the most variable over short periods of time, and is easiest to quantify (Amatya et al., 2009). 


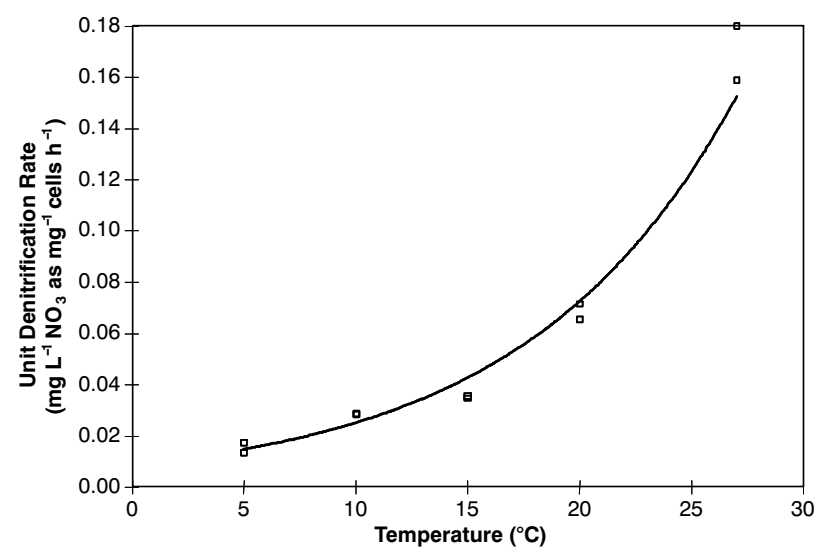

Figure 1. Exponential relationship of temperature to denitrification rate (data from Dawson and Murphy, 1972).

\section{Temperature Coefficient \\ DEVELOPMENT}

Denitrification in the sediments of drainage networks and natural streams, rivers, and lakes increases as the temperature increases. The relationship between the denitrification rate and temperature can be fitted with an empirical exponential curve, as shown by the data from Dawson and Murphy (1972) shown in figure 1.

Based on this exponential relationship, the removal rate $R R$ can be related to the temperature $T$ as in equation 6:

$$
R R=F^{*} \exp \left(B^{*} T\right)
$$

where $R R$ is the nitrate removal rate (in $\mathrm{mg} \mathrm{m}^{-2} \mathrm{~d}^{-1}$ for this derivation) at temperature $T\left({ }^{\circ} \mathrm{C}\right)$, and $F$ and $B$ are empirical constants. Using this relationship, two removal rates $\left(R R_{1}\right.$ and $R R_{2}$ ) can be related to each other with a temperature correction factor $\left(C_{T 1-T 2}\right.$, unitless) for a location and population of denitrifiers, as in equation 7 :

$$
\begin{aligned}
R R_{2} / R R_{1} & =F * \exp \left(B * T_{2}\right) / F * \exp \left(B * T_{1}\right) \\
& =C_{T 1-T 2}
\end{aligned}
$$

The temperature correction factor can be inserted into equation 4 in the following manner. Solving for $R R_{1}$ in equation 7 results in:

$$
R R_{1}=R R_{2} / C_{T 1-T 2}
$$

For this relationship to be useful, though, the constant $B$ must be determined. This is done as follows. Starting with the equation:

$$
C_{T 1-T 2}=F^{*} \exp \left(B^{*} T_{2}\right) / F^{*} \exp \left(B^{*} T_{1}\right)
$$

cancelling the $F$ terms and multiplying both sides by $\exp \left(B^{*} T_{1}\right)$, the equation becomes:

$$
C_{T 1-T 2} * \exp \left(B^{*} T_{1}\right)=\exp \left(B^{*} T_{2}\right)
$$

Taking the natural $\log (\ln )$ of both sides of the equation:

$$
\ln \left[C_{T 1-T 2} * \exp \left(B^{*} T_{1}\right)\right]=\ln \left[\exp \left(B^{*} T_{2}\right)\right]
$$

the equation becomes:

$$
\ln \left(C_{T 1-T 2}\right)+\ln \left[\exp \left(B^{*} T_{1}\right)\right]=\ln \left[\exp \left(B^{*} T_{2}\right)\right]
$$

which reduces to:

$$
\ln \left(C_{T 1-T 2}\right)+\left(B^{*} T_{1}\right)=\left(B^{*} T_{2}\right)
$$

By algebraic manipulation the equation becomes:

$$
\ln \left(C_{T 1-T 2}\right)=B^{*}\left(T_{2}-T_{1}\right)
$$

which can be solved for $B$ :

$$
B=\ln \left(C_{T 1-T 2}\right) /\left(T_{2}-T_{1}\right)
$$

Now by making the decision to base the equation on a $10^{\circ} \mathrm{C}$ increase in temperature from $T_{1}$, the base temperature, to $T_{2}$ with the notation $C_{10}, T_{2}$ becomes $\left(T_{1}+10\right)$ and $C_{T 1-T 2}$ becomes $C_{10}$, resulting in the equation:

$$
B=\ln \left(C_{10}\right) /\left(T_{1}+10-T_{1}\right)
$$

which reduces to:

$$
B=\ln \left(C_{10}\right) / 10
$$

If both sides are multiplied by $\left(T_{2}-T_{1}\right)$. the equation becomes:

$$
\left(T_{2}-T_{1}\right) * B=\left(T_{2}-T_{1}\right) / 10 * \ln \left(C_{10}\right)
$$

which can be rewritten as:

$$
\left(T_{2}-T_{1}\right)^{*} B=\ln \left(C_{10}(T 2-T 1) / 10\right)
$$

The equation is then multiplied out and the inverse natural $\log \left(\mathrm{e}^{x}\right)$ taken, making it an exponential equation:

$$
\exp \left(B^{*} T_{2}-B^{*} T_{1}\right)=\exp \left[\ln \left(\mathrm{C}_{10}\left(^{(T 2-T 1) / 10}\right)\right]\right.
$$

which can be rearranged into:

$$
\exp \left(B^{*} T_{2}\right) / \exp \left(B^{*} T_{1}\right)=\exp \left[\ln \left(C_{10}(T 2-T 1) / 10\right)\right]
$$

which reduces to:

$$
\exp \left(B^{*} T_{2}\right) / \exp \left(B^{*} T_{1}\right)=C_{10}(T 2-T 1) / 10
$$

From equation 7 it is known that:

$$
\exp \left(B^{*} T_{2}\right) / \exp \left(B^{*} T_{1}\right)=C_{T 1-T 2}
$$

which leads to the conclusion that:

$$
C_{T 1-T 2}=C_{10}{ }^{(T 2-T 1) / 10}
$$

This should start looking familiar as $C_{T 1-T 2}=R R_{2} / R R_{1}$, meaning that:

$$
R R_{2} / R R_{1}=C_{10}(T 2-T 1) / 10
$$

If the natural $\log (\ln )$ is taken of both sides, the equation becomes:

$$
\ln \left(R R_{2} / R R_{1}\right)=\ln \left(C_{10}^{(T 2-T 1) / 10}\right)
$$

which is equal to:

$$
\ln \left(R R_{2} / R R_{1}\right)=\left(T_{2}-T_{1}\right) / 10 * \ln \left(C_{10}\right)
$$

which after dividing by $\left(T_{2}-T_{1}\right) / 10$ is:

$$
10 /\left(T_{2}-T_{1}\right) * \ln \left(R R_{2} / R R_{1}\right)=\ln \left(C_{10}\right)
$$

Rewriting the equation yields:

$$
\ln \left(R R_{2} / R R_{1}\right)^{10 /(T 2-T 1)}=\ln \left(C_{10}\right)
$$

If the inverse natural log is now taken, the equation becomes:

$$
C_{10}=\left(R R_{2} / R R_{1}\right)^{10 /(T 2-T 1)}
$$

which is the temperature coefficient $Q_{10}$. This is the factor at which the rate of a reaction increases with a temperature increase of $10^{\circ} \mathrm{C}$. The $Q_{10}$ coefficient has an effective range of approximately $0^{\circ} \mathrm{C}$ to $40^{\circ} \mathrm{C}$ (Gillooly et al., 2001). 
Equation 8 can now be equated to equation 3, also solved for $R R$ (assuming that $R R$ in eq. $3=R R_{1}$ in eq. 8 ), resulting in equation 9:

$$
R R_{2} / C_{T 1-T 2}=\rho_{T 1} *[C]
$$

where $R R_{2}$ is the nitrate removal rate at temperature $T_{2}(\mathrm{mg}$ $\left.\mathrm{m}^{-2} \mathrm{~d}^{-1}\right), C_{T 1-T 2}$ is the correction factor for the change in the denitrification rate between the two temperatures (unitless), $\rho_{T 1}$ is the mass transfer coefficient for denitrification at temperature $T_{1}\left(\mathrm{~m} \mathrm{~d}^{-1}\right)$, and $[C]$ is the nitrate concentration $\left(\mathrm{mg} \mathrm{m}^{-3}\right)$. Rearranging equation 9 results in equation 10 :

$$
R R_{2}=\rho_{T 1} *[C]^{*} C_{T 1-T 2}
$$

The next step is to convert the denitrification rate $\left(R R_{2}\right.$, $\left.\mathrm{mg} \mathrm{m}^{-2} \mathrm{~d}^{-1}\right)$ to a mass denitrified $\left(R_{T 2}, \mathrm{mg}\right)$ by multiplying both sides by a sediment surface area $\left(A, \mathrm{~m}^{2}\right)$ and a time interval $(\Delta t, \mathrm{~d})$ :

$$
A^{*} \Delta t^{*} R R_{2}=\rho_{T 1} *[C] * C_{T 1-T 2} * A^{*} \Delta t
$$

This results in equation 11 , where $R_{T 2}$ is the mass of nitrate removed $(\mathrm{mg})$ at temperature $T_{2}$ during the time step $\Delta t$ over the area $A$ :

$$
R_{T 2}=\rho_{T 1} *[C]^{*} C_{T 1-T 2} * A * \Delta t
$$

The mass of nitrate removed can also be determined using a mass balance of the nitrate at the beginning of the time step and the end of the time step $(\Delta t)$ using the following equation:

$$
R=\left(\left[C_{0}\right]-\left[C_{1}\right]\right)^{*} A^{*} D
$$

where $R$ is the mass of nitrate removed $(\mathrm{mg}),\left[C_{0}\right]$ is the initial nitrate concentration at the beginning of time step $\Delta t$ $\left(\mathrm{mg} \mathrm{m}^{-3}\right),\left[C_{1}\right]$ is the final nitrate concentration at the end of time step $\Delta t\left(\mathrm{mg} \mathrm{m}^{-3}\right), A$ is the sediment surface area $\left(\mathrm{m}^{2}\right)$, and $D$ is the depth of the water column $(\mathrm{m}) . R$ is independent of temperature, as temperature is not represented in the previous equation. In this case, $R$ at temperature $T_{2}$ is of interest, so $R$ is determined for temperature $T_{2}\left(R_{T 2}\right.$ is the mass of nitrate removed, in $\mathrm{mg}$, at temperature $T_{2}$ during the time step $\Delta t$ over area $A$ ). This results in equation 12 :

$$
R_{T 2}=\left(\left[C_{0}\right]-\left[C_{1}\right]\right)^{*} A^{*} D
$$

Equation 11 can now be equated to equation 12:

$$
\left(\left[C_{0}\right]-\left[C_{1}\right]\right)^{*} A^{*} D=\rho_{T 1} *[C]^{*} C_{T 1-T 2} * A^{*} \Delta t
$$

which can be reduced to:

$$
\left(\left[C_{0}\right]-\left[C_{1}\right]\right) * D=\rho_{T 1} *[C] * C_{T 1-T 2} * \Delta t
$$

By rearranging the terms and multiplying through by -1 , the equation is converted to:

$$
\left(\left[C_{1}\right]-\left[C_{0}\right]\right) / \Delta t=\left(-\rho_{T 1} *[C]^{*} C_{T 1-T 2}\right) / D
$$

Taking the limit as the time step approaches zero:

$$
\lim (\Delta t \rightarrow 0)\left(\left[C_{1}\right]-\left[C_{0}\right]\right) / \Delta t=\left(-\rho_{T 1} *[C]^{*} C_{T 1-T 2}\right) / D
$$

where $\lim (\Delta t \rightarrow 0)\left(\left[C_{1}\right]-\left[C_{0}\right]\right) / \Delta t=d c / d t$

The average change in concentration over the time interval results in a differential equation:

$$
d c / d t=\left(-\rho_{T 1} *[C] * C_{T 1-T 2}\right) / D
$$

Separating terms and integrating concentration and time over the intervals $\left[C_{0}\right]$ to $\left[C_{1}\right]$ and 0 to $t$ yields:

$$
\int_{C 0}^{C 1} \frac{d c}{[C]}=\int_{0}^{t}-\rho_{T 1} * d t * \frac{C_{T 1-T 2}}{D}
$$

which results in:

$$
\ln \left(\left[C_{1}\right]\right)-\ln \left(\left[C_{0}\right]\right)=\left(-\rho_{T 1} * t^{*} C_{T 1-T 2}\right) / D
$$

Rearranging the terms yields:

$$
\ln \left(\frac{\left[C_{1}\right]}{\left[C_{0}\right]}\right)=-\rho_{T 1} * t * \frac{C_{T 1-T 2}}{D}
$$

Raising both sides of the equation to the exponential $\left(\mathrm{e}^{x}\right)$ and rearranging, the equation to model denitrification in a system with a variable temperature is derived (eq. 13):

$$
\left[C_{1}\right]=\left[C_{0}\right]^{*} \exp \left(-\rho_{T 1} * t^{*} C_{T 1-T 2} / D\right)
$$

By comparing equation 4 and equation 13, it can be deduced that the mass transfer coefficient $(\rho)$ can easily be related to a change in temperature by equation 14 :

$$
\rho_{T 2}=C_{T 1-T 2}{ }^{*} \rho_{T 1}
$$

where $\rho_{T 1}$ is the mass transfer coefficient at the original temperature $T_{1}\left(\mathrm{~m} \mathrm{~d}^{-1}\right), \rho_{T 2}$ is the mass transfer coefficient at a second temperature $T_{2}\left(\mathrm{~m} \mathrm{~d}^{-1}\right)$, and $C_{T 1-T 2}$ is the correction factor for the change in temperature (unitless).

\section{Methods}

Equations 1, 4, and 13 were tested using data collected in field experiments. Nitrate removal rates were determined in tanks inserted in a stream in a forested watershed during two time periods with different temperature ranges. The three equations $(1,4$, and 13$)$ were used to predict nitrate removal in the tanks during the studies. Predicted nitrate concentrations were compared to measured nitrate concentrations.

\section{FiELd EXPERIMENT DESCRIPTION}

The field study was located in Washington County, near Plymouth, in the coastal plain of North Carolina (fig. 2). The 10,000 ha watershed drains into the Albemarle Sound through a five-mile stretch of Kendrick's Creek. The portion of the watershed used for this study consists of approximately 4,000 ha of managed forest. The soils of the study location are organic soils (Belhaven series; loamy, mixed, dysic, thermic Terric Medisaprists) (SCS, 1981).

A $1900 \mathrm{~m}$ section of a forest drainage canal, from S0 to S3 (fig. 2), averaging $4 \mathrm{~m}$ in top width, $1.4 \mathrm{~m}$ in depth, average sideslope of $1: 1$, and overall bottom slope of 0.0003 , was selected for the study. A litter layer ( $4 \mathrm{~cm}$ thick) and organic layer ( $\sim 20 \mathrm{~cm}$ thick) cover the bottom of the canal. Below $\sim 20 \mathrm{~cm}$ there is a thick sand layer underlain by a very tight clayey layer.

Water column nitrate depletion was measured in three instream tanks. The tanks were constructed of a section of PVC pipe $43 \mathrm{~cm}$ in diameter (fig. 3) and positioned in the center of the canal at three locations between S0 and S3 (fig. 2). A base for each tank was installed into the sediment during the dry season. The bases were also made of $43 \mathrm{~cm}$ diameter PVC pipe and driven $23 \mathrm{~cm}$ into the sediment. A $1 \mathrm{~m} \times 1 \mathrm{~m}$ square PVC plate with a $43 \mathrm{~cm}$ hole cut into the middle was attached to the top of the base at the surface of the sediment to keep the tank from sinking into the sediment. A stainless steel ring 


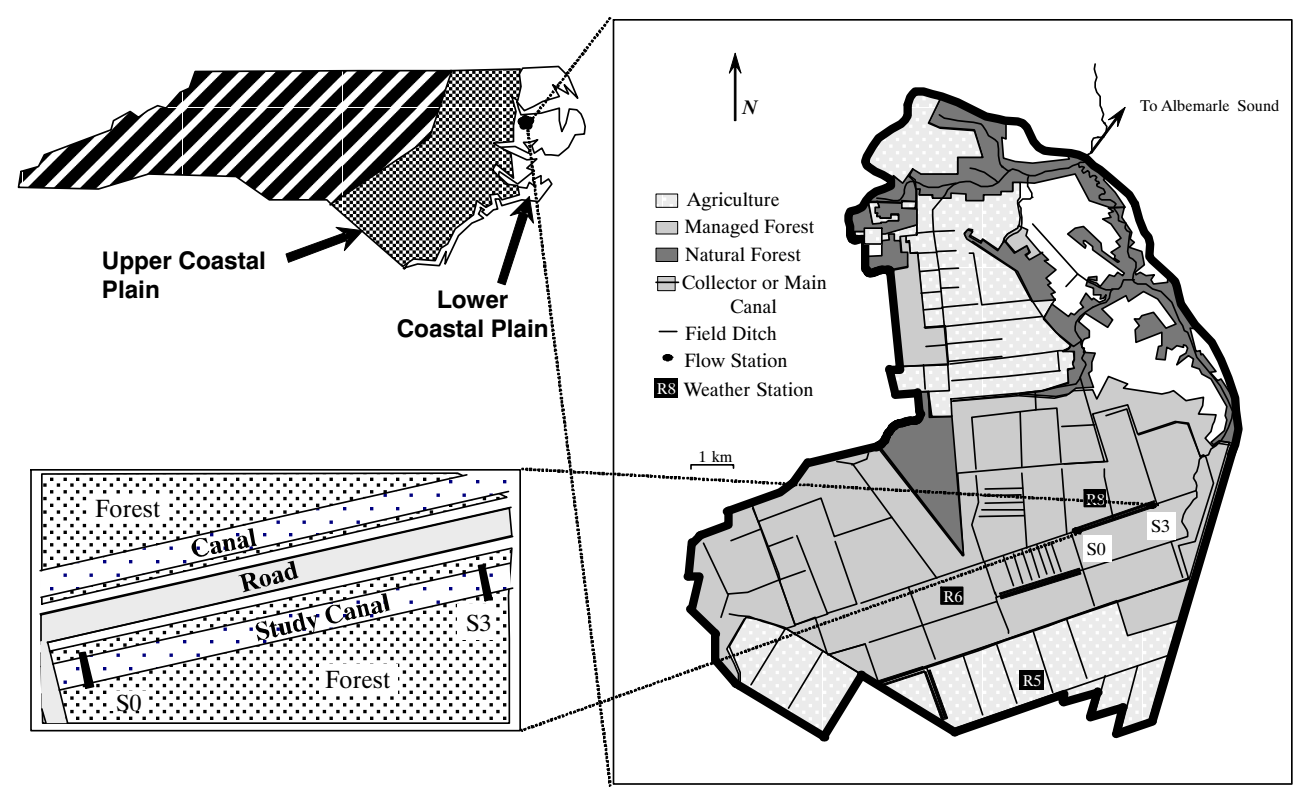

Figure 2. Location of Parker Tract watershed and canal study site.

was attached to the base. This ring extended upward $7.5 \mathrm{~cm}$ into the water column from the sediment surface. The tank slid onto this ring to form a seal to separate the water inside the tank from the canal water outside the tank. A neoprene rubber ring was placed between the tank and the base to ensure a watertight seal.

The tanks were placed in the canal after each of two rainfall events to take advantage of the naturally occurring nitrate peak following each rainfall event. Grab samples were taken periodically after tank placement (see fig. 5 for sampling times). Samples were taken within the tank at middepth of the water column. Each sample consisted of $25 \mathrm{~mL}$ of water from the water column. All three tanks were sampled at the same time. Water samples were placed on ice immediately after collection and frozen until analysis. All samples were filtered through a $0.45 \mu \mathrm{m}$ filter (Supor-450, Gelman Laboratory) to remove particulate material. Each sample was analyzed for nitrate, ammonium, phosphate, and dissolved organic carbon (APHA, 1989).

Temperatures within the in-stream tanks varied with the ambient air temperature. Hourly mid-depth water column temperatures were measured outside the tank in a companion study (Appelboom, 2004). Mid-depth water column

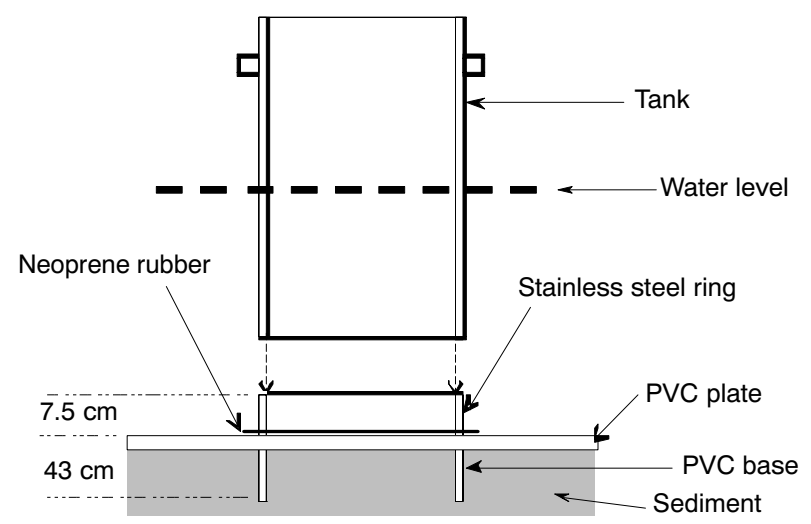

Figure 3. In-stream denitrification tank. temperatures were also manually measured within the tanks at the time of sample collection for comparison to the hourly temperature record. The two temperatures were within $0.5^{\circ} \mathrm{C}$ for all comparative readings. This verified that the hourly data could be used to make hourly time step nitrate concentration predictions to compare to the measured nitrate concentrations for each tank. The midpoint was chosen as it was a convenient location to measure without disturbing the tank and related to water column temperatures taken by flowmeters and other commonly used stream monitoring equipment. The mass transfer coefficients $\left(\rho_{T 1}\right)$ used in equations 4 and 13 were determined at $8^{\circ} \mathrm{C}$.

Water in the tanks was not continuously circulated due to the absence of a power source at the site. A companion study at this location showed there was no significant difference between the nitrate removal in circulated and non-circulated tanks (Appelboom, 2004). Dissolved oxygen and pH were also measured at mid-depth in the water column within the tank and in the open canal at each sampling for comparison.

\section{EquATION CoMParisons}

The mass transfer coefficients were determined using a companion study. In that study, undisturbed cores were taken from the three locations of the in-stream tanks. The cores were taken approximately $2 \mathrm{~m}$ from each of the in-stream tanks at the time the bases were installed. The cores were placed in chambers in the lab, filled to the same depth with water, and placed in a cold room at $8^{\circ} \mathrm{C}$ (Appelboom, 2004). The nitrate concentration in each tank was brought up to $6 \mathrm{mg}$ $\mathrm{L}^{-1}$. Samples were taken over time to determine nitrate removal rates and mass transfer coefficients for each tank. Site-specific mass transfer coefficients were used for each of the three locations where the in-stream tanks were placed. An overall average mass transfer coefficient was also used to determine how well the two equations perform using an average value. This overall average mass transfer coefficient was the average of the three site-specific mass transfer coefficients.

The temperature correction factor was determined using equation 7; $T_{1}$ was equal to $8^{\circ} \mathrm{C}$ due to the mass transfer 
coefficients being determined in the undisturbed core companion study at $8^{\circ} \mathrm{C}$, and $T_{2}$ was the measured water column temperature at each time step. Each time step was $1 \mathrm{~h}$. Field-collected water column nitrate concentrations were compared to predicted water column nitrate concentrations using equations 1, 4, and 13. Each predicted concentration was based on the previous time step prediction ( $C_{1}$ was based on $C_{0}, C_{2}$ was based on $C_{1}, C_{3}$ was based on $C_{2}$, and so on). $C_{0}$ for all predicted concentrations was the initial measured concentration. Comparisons were conducted using regression analysis of predicted concentrations versus measured concentrations.

\section{RESUlts AND Discussion}

Water column temperatures ranged from $6^{\circ} \mathrm{C}$ to $17^{\circ} \mathrm{C}$ during the first run and from $13{ }^{\circ} \mathrm{C}$ to $22^{\circ} \mathrm{C}$ during the second run (fig. 4). This gave a wide range of temperatures for testing the predicting accuracy of the three equations (eqs. 1, 4, and 13). As stated in the Methods section, the midpoint water column temperature was chosen for the calculations in this article since it was a convenient location to measure without disturbing the tank and related to water column temperatures taken by flowmeters and other commonly used stream monitoring equipment. The companion study mentioned in

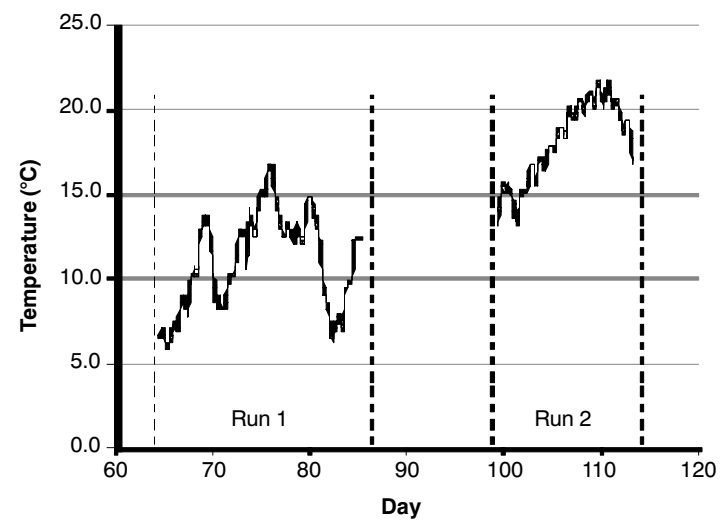

Figure 4. Hourly midpoint water temperatures.

the Methods section also measured temperatures in the litter layer on the bottom of the canal, $5 \mathrm{~cm}$ below the sediment surface, and the air temperature above the water surface with the exception of one exceptionally warm day and one exceptionally cold night. The water column, litter layer, and sediment temperatures were all very similar with little to no difference. The air temperatures varied greatly, with the daytime temperatures always higher and the nighttime temperature always lower than the other three temperatures.
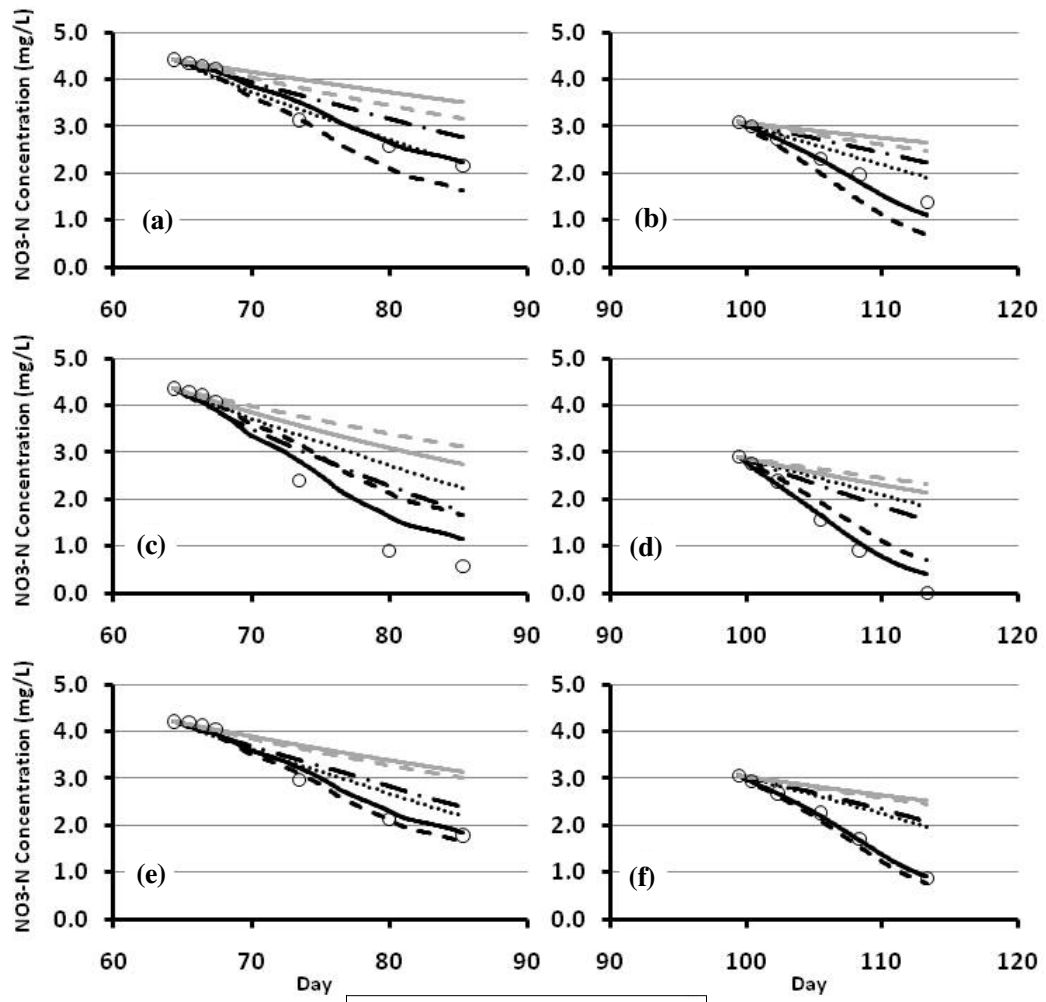

Measured NO3-N
- Eq. 1 with Site Specific $\rho$
-- Eq. 1 with Average $\rho$
.- Eq. 4 with Site Specific $\rho$
$\ldots . .$. Eq. 4 with Average $\rho$
- Eq. 13 with Site Specific $\rho$
-- Eq. 13 with Average $\rho$

Figure 5. Measured and predicted water column nitrate concentrations in in-stream tanks over time: (a) location 1 - run 1, (b) location 1 - run 2, (c) location 2 - run 1, (d) location 2 - run 2, (e) location 3 - run 1, and (f) location 3 - run 2. Site-specific mass transfer coefficients ( $\rho$ ) were 0.011 for location 1 , 0.022 for location 2 , and 0.014 for location 3 . The average mass transfer coefficient $(\rho)$ was 0.016 . Predicted concentrations were made using equations 1,4 , and 13 with both a site-specific mass transfer coefficient and a study-average mass transfer coefficient. 
Table 1. Regression analysis $\mathbf{R}^{\mathbf{2}}$ values and Nash-Sutcliffe model efficiency (E) values for the comparison of measured nitrate concentrations versus predicted nitrate concentrations over time using equations 1,4 , and 13 .

\begin{tabular}{|c|c|c|c|c|c|c|}
\hline & \multicolumn{2}{|c|}{$\begin{array}{c}\text { Predicted Nitrate Concentrations } \\
\text { Using Standard Decay Equation } \\
\text { (eq. 1) }\end{array}$} & \multicolumn{2}{|c|}{$\begin{array}{l}\text { Predicted Nitrate Concentrations } \\
\text { without Temperature Component } \\
\text { (eq. } 4)\end{array}$} & \multicolumn{2}{|c|}{$\begin{array}{c}\text { Predicted Nitrate Concentrations } \\
\text { with Temperature Component } \\
\text { (eq. 13) }\end{array}$} \\
\hline & $\mathrm{R}^{2}$ & $\mathrm{E}$ & $\mathrm{R}^{2}$ & $\mathrm{E}$ & $\mathrm{R}^{2}$ & $\mathrm{E}$ \\
\hline \multicolumn{7}{|c|}{ Location 1 , Run 1 , Temp. $6^{\circ} \mathrm{C}$ to $14^{\circ} \mathrm{C}$} \\
\hline Location $\rho^{[\mathrm{a}]}=0.011$ & 0.98 & 0.28 & 0.98 & 0.82 & 0.98 & 0.97 \\
\hline Average $\rho^{[b]}=0.016$ & 0.99 & 0.59 & 0.99 & 0.98 & 0.98 & 0.90 \\
\hline \multicolumn{7}{|c|}{ Location 2 , Run 1 , Temp. $6^{\circ} \mathrm{C}$ to $14^{\circ} \mathrm{C}$} \\
\hline Location $\rho^{[\mathrm{a}]}=0.022$ & 0.98 & 0.35 & 0.98 & 0.77 & 0.99 & 0.94 \\
\hline Average $\rho^{[b]}=0.016$ & 0.98 & 0.13 & 0.98 & 0.58 & 0.99 & 0.80 \\
\hline \multicolumn{7}{|c|}{ Location 3 , Run 1 , Temp. $6^{\circ} \mathrm{C}$ to $14^{\circ} \mathrm{C}$} \\
\hline Location $\rho^{[\mathrm{a}]}=0.014$ & 0.99 & 0.40 & 0.98 & 0.84 & 0.99 & 0.98 \\
\hline Average $\rho^{[b]}=0.016$ & 0.99 & 0.50 & 0.98 & 0.90 & 0.99 & 0.99 \\
\hline \multicolumn{7}{|c|}{ Location 1 , Run 2 , Temp. $13^{\circ} \mathrm{C}$ to $20^{\circ} \mathrm{C}$} \\
\hline Location $\rho^{[\mathrm{a}]}=0.011$ & 1.00 & -0.25 & 1.00 & 0.43 & 1.00 & 0.96 \\
\hline Average $\rho^{[b]}=0.016$ & 1.00 & 0.08 & 1.00 & 0.77 & 1.00 & 0.59 \\
\hline \multicolumn{7}{|c|}{ Location 2 , Run 2 , Temp. $13^{\circ} \mathrm{C}$ to $20^{\circ} \mathrm{C}$} \\
\hline Location $\rho^{[\mathrm{a}]}=0.022$ & 1.00 & -0.20 & 1.00 & 0.36 & 1.00 & 0.96 \\
\hline Average $\rho^{[b]}=0.016$ & 1.00 & -0.42 & 1.00 & 0.09 & 1.00 & 0.87 \\
\hline \multicolumn{7}{|c|}{ Location 3 , Run 2 , Temp. $13^{\circ} \mathrm{C}$ to $20^{\circ} \mathrm{C}$} \\
\hline Location $\rho^{[\mathrm{a}]}=0.014$ & 0.99 & -0.16 & 1.00 & 0.37 & 1.00 & 1.00 \\
\hline Average $\rho^{[b]}=0.016$ & 0.99 & -0.06 & 1.00 & 0.49 & 1.00 & 0.98 \\
\hline \multicolumn{7}{|c|}{ All Locations, All Runs, Temp. $6^{\circ} \mathrm{C}$ to $20^{\circ} \mathrm{C}$} \\
\hline Location $\rho^{[\mathrm{a}]}$ & 0.77 & 0.41 & 0.95 & 0.76 & 0.98 & 0.97 \\
\hline Average $\rho^{[b]}=0.016$ & 0.72 & 0.38 & 0.88 & 0.72 & 0.90 & 0.90 \\
\hline
\end{tabular}

[a] Location $\rho$ is the site-specific mass transfer coefficient for the location the tank was placed.

[b] Average $\rho$ is the average mass transfer coefficient for all the tank locations.

This indicates that, for this study and this site, the water column temperature is a good surrogate for the sediment temperature.

Dissolved oxygen in the tanks ranged from 4.2 to 8.9 and $\mathrm{pH}$ ranged from 3.3 to 6.8 during the study. These readings matched those taken in the water column outside the tanks. This indicates that the environmental conditions inside and outside the tanks were similar. No algal growth was observed in any of the tanks. There were also no submergent or emergent plants present, which is typical of this type of drainage network.

The basic decay equation (eq. 1) overpredicted the nitrate concentrations (underpredicting nitrate removal) in all cases, using both the site-specific and average mass transfer coefficient $(\rho)$ (fig. 5). The coefficients of determination $\left(R^{2}\right)$ ranged from 0.98 to 1.00 for both the site-specific and average mass transfer coefficients $(\rho)$ (table 1$)$. However, the coefficient of determination only tells us how well a straight line can describe the data, not how well that line matches the 1:1 relationship that is sought. Nash and Sutcliffe (1970) proposed a similar statistic, (E, the efficiency of a model), which tells us both how well a straight line can describe the relationship between the predicted and measured values and how close that line is to a 1:1 relationship. The Nash-Sutcliffe E ranged from -0.25 to 0.40 for the site-specific mass transfer coefficients $(\rho)$ and from -0.42 to 0.59 for the average mass transfer coefficient $(\rho)$ (table 1$)$. This tells us that even though the relationships between the predicted and measured values have high $\mathrm{R}^{2}$ values, each of the lines deviate a great deal from the 1:1 relationship of a perfect slope fit, resulting in very poor predictions for the most part.

Equation 4, without a temperature coefficient, overpredicted the nitrate concentration in all instances, except for the case when the average mass transfer coefficient ( $\rho)$ was used to predict concentrations for the first run at location 1 (fig. 5). The coefficients of determination $\left(\mathrm{R}^{2}\right)$ ranged from 0.98 to 1.00 for the site-specific mass transfer coefficient and from 0.99 to 1.00 for the average mass transfer coefficient (table 1). The Nash-Sutcliffe E ranged from 0.36 to 0.84 for the site-specific mass transfer coefficient and from 0.09 to 0.98 for the average mass transfer coefficient (table 1). Again, each regression line deviated from the 1:1 relationship of a perfect slope fit, resulting in poor predictions for the most part. The overpredicted concentrations are likely due to the mass transfer coefficient $(\rho)$ being determined at a lower temperature than occurred during the experiment, which results in lower nitrate removal rate predictions and smaller changes in the concentration than actually occurred. Had the mass transfer coefficient been determined at a higher temperature than occurred during the runs, the concentration predictions of equation 4 would have likely been lower than the measured values.

The equation that included the temperature component (eq. 13) resulted in very close fits to the measured data when the site-specific mass transfer coefficients were used $\left(\mathrm{R}^{2}\right.$ values ranged from 0.98 to 1.00 ; table 1 and fig. 5). When the average mass transfer coefficient $(\rho=0.016)$ was used, there was still good agreement among the individual runs $\left(\mathrm{R}^{2}\right.$ values ranged from 0.98 to 1.00 ; table 1 ). The Nash-Sutcliffe E ranged from 0.94 to 1.00 for the site-specific mass transfer coefficient and from 0.59 to 0.99 for the average mass transfer coefficient (table 1). The Nash-Sutcliffe E for all the predictions using the site-specific mass transfer coefficients and most using the average mass transfer coefficient showed regression lines close to the desired 1:1 relationship to the measured nitrate concentration values. Figures $5 \mathrm{e}$ and $5 \mathrm{f}$ 
particularly show very good results, with the equation 13 predictions curving to match the measured data.

When the data points from all the runs were pooled into one regression analysis, the $\mathrm{R}^{2}$ value for equation 13 was only slightly higher than that of equation 4 for both the sitespecific and average mass transfer coefficients (fig. 6). Equations 13 and 4 both had higher $\mathrm{R}^{2}$ values than equation 1. The Nash-Sutcliffe E, on the other hand, was much higher for equation 13 than for equation 4, which was much higher than equation 1 . When the site-specific mass transfer coefficient was used, the $\mathrm{R}^{2}$ was 0.98 and NashSutcliffe E was 0.97 for equation $13 ; 0.95$ and 0.76 respectively, for equation 4 ; and 0.77 and 0.41 , respectively, for equation 1 . When the average mass transfer coefficient $\rho=0.016$ ) was used, the $\mathrm{R}^{2}$ was 0.90 and Nash-Sutcliffe E was 0.90 for equation $13 ; 0.88$ and 0.72 , respectively, for equation 4; and 0.72 and 0.38 , respectively, for equation 1 . The fact that the coefficient of determination and the NashSutcliffe E are similar for equation 13 indicates that the regression lines were close to the desired 1:1 relationship between the predicted and measured nitrate concentration values. The difference in the coefficient of determination and the Nash-Sutcliffe $\mathrm{E}$ for equation 4 indicates that the regression line is not as close to the 1:1 relationship as it is for equation 13. The large difference between the coefficient of determination and the Nash-Sutcliffe $E$ for equation 1 indicates that the regression line is not nearly as close to the $1: 1$ relationship as it is for equation 13 .
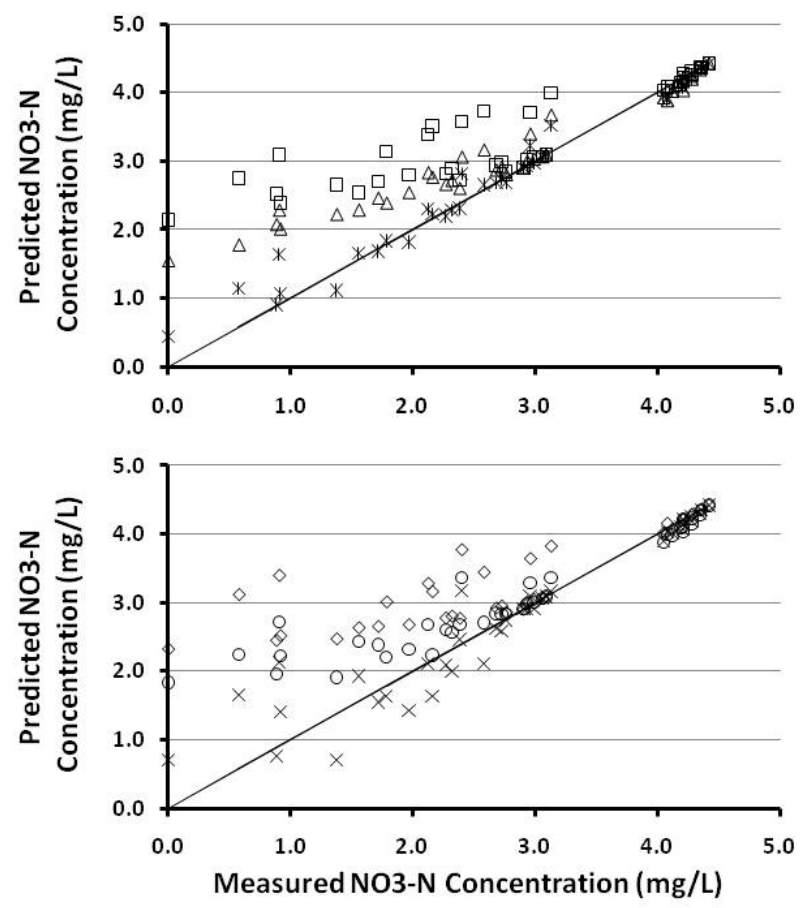

$$
\begin{array}{ll}
\hline & \text { Eq. } 1 \text { with Site Specific } \rho \\
\diamond & \text { Eq. } 1 \text { with Average } \rho \\
\Delta & \text { Eq. } 4 \text { with Site Specific } \rho \\
\circ & \text { Eq. } 4 \text { with Average } \rho \\
X & \text { Eq. } 13 \text { with Site Specific } \rho \\
X & \text { Eq. } 13 \text { with Average } \rho
\end{array}
$$

Figure 6. All data points from the two runs of the three in-stream tanks compared to their associated predicted nitrate concentrations using equations 1,4 , and 13 with both a site-specific mass transfer coefficient and a study-average mass transfer coefficient.
The improvement of equation 4 over equation 1 is attributed to the addition of the depth term to the equation. This term makes it possible to vary the mass transfer coefficient as the depth of the water column changes. The increase of the Nash-Sutcliffe E from 0.41 and 0.38 to 0.76 and 0.72 for the site-specific and average mass transfer coefficients, respectively, shows that the addition of the depth term was a substantial improvement to the basic decay equation.

The overall improved predictions with equation 13 as compared to equation 4 are attributed to the inclusion of the temperature term $\left(C_{T 1-T 2}\right)$. This term allows the equation to change the nitrate removal rate as both temperature and depth changes between each time step, resulting in a more accurate water column nitrate concentration prediction with time. The increase of the Nash-Sutcliffe E from 0.76 and 0.72 to 0.97 and 0.90 for the site-specific and average mass transfer coefficients, respectively, shows that the addition of the temperature term was another substantial improvement to the basic decay equation.

The improvement of the predictions using the site-specific mass transfer coefficient is due to the improved representation it gives the nitrate removal at each site as compared to the average mass transfer coefficient.

The range of the temperature term $\left(C_{T 1-T 2}\right)$ found in this study was 0.79 to 4.27 , based on the mass transfer coefficient determined at $8^{\circ} \mathrm{C}$. This range relates directly to a $Q_{10}$ value of 2.88. The $Q_{10}$ coefficient is generally approximated as 2 (i.e., a two-fold increase for each $10^{\circ} \mathrm{C}$ rise in temperature; Yu et al., 2006; Lewis, 2002; Martin, 2000; Ellis et al., 1998). Most studies found $Q_{10}$ values ranging from 1.3 to 3.0, although Ellis et al. (1998) reported a range from 0.5 to 20 for non-inundated soils.

There are several limitations with the use of equation 13 as it is currently presented. The first is the limitation based on the temperature range that constrains the temperature term $\left(C_{T 1-T 2}\right)$. As shown in the Temperature Coefficient Development section, the $C_{T 1-T 2}$ term is directly related to the $Q_{10}$ term. This means that, as a biological rate exponential relationship, it is constrained by the upper and lower temperature bounds of the organisms' activity. The $Q_{10}$ term has an effective range of approximately $0^{\circ} \mathrm{C}$ to $40^{\circ} \mathrm{C}$ (Gillooly et al., 2001), which means that this is also the range in which the $C_{T 1-T 2}$ term is valid.

A second limitation is that the equation was tested in noflow/low-flow conditions. This is representative of lake bottom or slow stream flow conditions, and this equation was developed for use in the Mid-Atlantic Coastal Plain, where slow-moving drainage networks are the norm. However, we believe that this equation would work well under higher flow conditions as well. This assumption is based on the fact that the predictions are keyed off of concentration values and calculated on removal rates per area $\left(\mathrm{mg} \mathrm{m}^{-2} \mathrm{~d}^{-1}\right)$, which will, to a point, be the same regardless of the flow. In the companion study, in which the mass transfer coefficient was determined, no differences were found between the circulated and non-circulated tanks, indicating that, at least at this study site, flow velocity was not as large a factor as it could be in other areas. It is the residence time that will change the amount of nitrate removed from a volume of water moving through the system, and this residence time is taken into account by the time step of the equation. This being said, 
equation 13 needs to be tested in higher flow conditions before it is used in such situations.

\section{Conclusion}

A relationship of denitrification rate to temperature was inserted into an equation using mass transfer coefficients to predict nitrate removal due to denitrification within drainage networks. The modified equation was tested by comparing predicted nitrate concentrations with nitrate concentrations measured over time in denitrification tanks at various temperatures. The modified equation improved the accuracy of the predicted concentrations when compared to the equation without the temperature adjustment. The use of the temperature adjustment improved the pooled Nash-Sutcliffe E from 0.76 to 0.97 when the site-specific mass transfer coefficient was used and from 0.72 to 0.90 when the average mass transfer coefficient was used, indicating a better regression fit as well as a closer 1:1 relationship between the predicted and measured nitrate concentrations. Caution should be used if equation 13 is implemented, as there are constrains on the equation. The temperature range is limited to the effective range of microbial activity $\left(0^{\circ} \mathrm{C}\right.$ to $\left.40^{\circ} \mathrm{C}\right)$, and until tested under other flow conditions, equation 13 cannot be used in higher flow conditions with confidence.

\section{ACKNOWLEDGEMENTS}

The authors wish to acknowledge Eugene Boyce, Wilson Huntley, and Jay Frick at North Carolina State University for their assistance in this study, and Joe Hughes, Joe Bergman, Jamie Nettles, and Cliff Tyson of the Weyerhaeuser Company for their cooperation and contributions to this study. We also wish to acknowledge the Weyerhaeuser Company on whose land this study was conducted. This research was conducted in the Department of Biological and Agricultural Engineering and the Department of Soil Science at North Carolina State University. The research was supported by funds from the U.S. EPA 319 program (Project Nos. EW9024 and EW8036), the Weyerhaeuser Company, the Water Resources Research Institute of the University of North Carolina Project No. 70162), and USDA-NCREES/ NRICGP (Project No. 98-35102-6493).

\section{REFERENCES}

Amatya, D. M., G. M. Chescheir, G. P. Fernandez, R. W. Skaggs, and J. W. Gilliam. 2004. DRAINWAT-based methods for estimating nitrogen transport in poorly drained watersheds. Trans. ASAE 47(3): 677-687.

Amatya, I. M., B. R. Kansakar, V. Tare, and L. Fiksdal. 2009. Impact of temperature on biological denitrification process. $J$. Inst. Eng. 7(1): 1-6.

APHA. 1989. Standard Methods for the Examination of Water and Waste Water. 17th ed. Washington, D.C.: American Public Health Association, American Waterworks Association, and Water Pollution Control Federation.

Appelboom, T. W. 2004. Effects of in-stream processes on the fate of nitrogen and phosphorous in drainage canals of forested watersheds. PhD diss. Raleigh, N.C.: North Carolina State University.

Arnold, J. G., R. Srinivasan, R. S. Muttiah, and J. R. Williams. 1998. Large-area hydrologic modeling and assessment: Part I.
Model development. J. American Water Resources Assoc. 34(1): 73-90.

Birgand, F. 2000. Quantification and modeling of in-stream processes in agricultural canals of the lower coastal plain. $\mathrm{PhD}$ diss. Raleigh, N.C.: North Carolina State University.

Birgand, F., R. W. Skaggs, G. M. Cheschier, and J. W. Gilliam. 2007. Nitrogen removal in streams of agricultural catchments: A literature review. Critical Reviews in Environ. Sci. and Tech. 37(5): 381-487.

Brown, L., K. Boone, S. Nokes, and A. Ward. 2009. Agricultural best management practices. Fact Sheet AEX-464-91. Columbus, Ohio: Ohio State University Extension. Available at: http://ohioline.osu.edu/aex-fact/0464.html.

Chalamet, A. 1985. Effects of environmental factors on denitrification. In Denitrification in the Nitrogen Cycle, 7-29. H. L. Golterman, ed. NATO Conference Series 1: Ecology, vol. 9. New York, N.Y.: Plenum Press.

Chatarpaul, L., J. B. Robinson, and N. K. Kaushik. 1979. Role of tubificid worms on nitrogen transformations in stream sediment. J. Fish. Res. Board of Canada 36(6): 673-678.

CWSRF. 1987. North Carolina construction grants and loans: Clean water state revolving fund. Raleigh, N.C.: North Carolina Department of Environment and Natural Resources. Available at: www.nccgl.net/fap/cwsrf/index.html.

Dawson, R. N., and K. L. Murphy. 1972. The temperature dependency of biological denitrification. Water Res. 6(1): 71-83.

Duff, J. H., and F. J. Triska. 1990. Denitrification in sediments from the hyporheic zone adjacent to a small forested stream. Canadian J. Fish. Aquat. Sci. 47(6): 1140-1147.

Ellis, S., S. Yamulki, E. Dixon, R. Harrison, and S. C. Jarvis. 1998. Denitrification and $\mathrm{N}_{2} \mathrm{O}$ emissions from a U.K. pasture soil following the early spring application of cattle slurry and mineral fertilizer. Plant and Soil 202(1): 15-25.

Fernandez, G. P., G. M. Chescheir, R. W. Skaggs, and D. M. Amatya. 2005. Development and testing of watershed-scale models for poorly drained soils. Trans. ASAE 48(2): 639-652.

Gillooly, J. F., J. H. Brown, G. B. West, V. M. Savage, and E. L. Charnov. 2001. Effects of size and temperature on metabolic rate. Science 293(5538): 2248-2251.

Heatwole, C. D., A. B. Bottcher, and K. L. Campbell. 1987. Basin-scale water quality model for coastal plain flatwoods. Trans. ASAE 30(4): 1023-1030.

Hill, A. R. 1988. Factors influencing nitrate depletion in a rural stream. Hydrobiologia 160(2): 111-122.

Hill, A. R., and K. Sanmugadas. 1985. Denitrification rates in relation to stream sediment characteristics. Water Res. 19(12): 1579-1586.

Hynes, H. B. N. 1983. Groundwater and stream ecology. Hydrobiologia 100(1): 93-99.

Jensen. K., N. P. Sloth, N. Risgaard-Petersen, S. Rysgaard, and N. P. Revsbech. 1994. Estimation of nitrification and denitrification from microprofiles of oxygen and nitrate in model sediment systems. Appl. Environ. Microbiol. 60(6): 2094-2100.

Kelly, C. A., J. W. M. Rudd, R. H. Hesslein, D. W. Schindler, P. J. Dillon, C. T. Driscoll, S. A. Gherini, and R. E. Hecky. 1987. Prediction of biological acid neutralization in acid-sensitive lakes. Biogeochem. 3: 129-140.

Lewis, W. M. 2002. Causes for the high frequency of nitrogen limitation in tropical lakes. Verh. Intl. Verein Limnol. 28(): 210-213.

Martin, L. A. 2000. Denitrification in sediments of headwater streams in the southern Appalachian Mountains, USA. MS thesis. Blacksburg, Va.: Virginia Polytechnic Institute and State University.

Meyer, J. L., G. E. Likens, and J. Sloane. 1981. Phosphorous, nitrogen, and organic carbon flux in a headwater stream. Arch. Hydrobiol. 91(1): 28-44. 
Nash, J. E., and J. V. Sutcliffe. 1970. River flow forecasting through conceptual models: Part 1. A discussion of principles. J. Hydrol. 10(3): 282-290.

Nowicki, B. L. 1994. The effect of temperature, oxygen, salinity, and nutrient enrichment on estuarine denitrification rates measured with a modified nitrogen gas flux technique. Estuarine, Coastal and Shelf Sci. 38(2): 137-156.

NRC. 2000. Clean coastal waters: Understanding and reducing the effects of nutrients pollution. Washington, D.C.: National Research Council, Committee on the Causes and Management of Eutrophication.

NRCS. 2009. National Conservation Practices Standards - NHCP. Washington, D.C.: USDA Natural Resources Conservation Service. Available at: www.nrcs.usda.gov/technical/ Standards/nhcp.html.

Poor, N., R. Pribble, and H. Greening. 2001. Direct wet and dry deposition of ammonia, nitric acid, ammonium, and nitrate to the Tampa Bay estuary, FL, USA. Atmos. Environ. 35(23): 3947-3955.

Rabalais, N. N., R. E. Turner, and D. Scavia. 2002. Beyond science into policy: Gulf of Mexico hypoxia and the Mississippi River. Bioscience 52(2): 129-142.

SCS. 1981. Soil survey of Washington County, North Carolina. Washington, D.C.: USDA Soil Conservation Service.
Seitzinger, S. P. 1988. Denitrification in freshwater and coastal marine ecosystems: Ecological and geochemical significance. Limnol. Oceanogr. 33(4): 702-704.

Skaggs, R. W., and G. M. Chescheir. 1999. Application of drainage simulation models. In Agricultural Drainage, 537-566. Agronomy Monograph 38. Madison, Wisc.: ASA.

Smith, V. H., G. D. Tilman, and J. C. Nekola. 1999. Eutrophication: Impacts of excess nutrient inputs on freshwater, marine, and terrestrial ecosystems. Environ. Pollution 100(1-3): 179-196.

Swank, W. T., and W. H. Caskey. 1982. Nitrate depletion in a second-order mountain stream. J. Environ. Qual. 11(4): 581-584.

Tisdale, S. L., W. L. Nelson, J. D. Beaton, and J. L. Havlin. 1993. Soil Fertility and Fertilizers. 5th ed. New York, N.Y.: Macmillan.

Triska, F. J., J. R. Sedell, K. Cromack Jr., S. V. Gregory, and F. M. McCorison. 1984. Nitrogen budget for a small coniferous forest stream. Ecol. Monogr. 54(1): 119-140.

Van Kessel, J. F. 1977. Factors affecting the denitrification rate in two water sediment systems. Water Res. 11(3): 259-267.

Wyer, M., and D. Kay. 1989. Experimental assessment of rates of nitrate removal by river bed sediments. J. Inst. Water Environ. Mgmt. 3(3): 273-279.

Yu, K., R. D. Delaune, and P. Boeckx. 2006. Direct measurement of denitrification activity in a Gulf Coast freshwater marsh receiving diverted Mississippi River water. Chemosphere 65(11): 2449-2455. 